JGRADASI TEKnIK SIPIL 


\section{JURNAL GRADASI TEKNIK SIPIL POLITEKNIK NEGERI BANJARMASIN}

Jurnal Gradasi Teknik Sipil diterbitkan oleh Pusat Penelitian dan Pengabdian Kepada Masyarakat Politeknik Negeri Banjarmasin. Ruang lingkup makalah meliputi Bidang Teknik dan Manajemen dengan konsentrasi Bidang Transportasi, Geoteknik, Struktur, Keairan dan Manajemen Konstruksi. Isi makalah dapat berupa penyajian isu aktual di bidang Teknik Sipil, review terhadap perkembangan penelitian, pemaparan hasil penelitian, dan pengembangan metode, aplikasi, dan prosedur di bidang Teknik Sipil. Makalah ditulis mengikuti panduan penulisan.

\section{Penanggung Jawab}

Nurmahaludin, ST, MT.

\section{Dewan Redaksi}

Ketua :

Anggota : Riska Hawinuti, ST, MT.

Nurfitriah, S.Pd, MA.

Ir. Rusliansyah, M.Sc.

\section{Reviewer}

Dr. Ir. Yanuar Jarwadi Purwanto, MS. (Institut Pertanian Bogor)

Dr. Ir. Achmad Rusdiansyah, MT. (Universitas Lambung Mangkurat)

Dr. Ir. M. Azhar, M. Sc. (Institut Sains dan Teknologi Nasional)

Dr. Ir. Endang Widjajanti, MT. (Institut Sains dan Teknologi Nasional)

Joni Irawan, ST, MT. (Politeknik Negeri Banjarmasin)

Yusti Yudiawati, ST, MT. (Politeknik Negeri Banjarmasin)

\section{Editing dan Tata Bahasa}

Nurfitriah, S.Pd., MA.

\section{Desain dan Tata Letak}

Abdul Hafizh Ihsani

\section{Alamat Redaksi}

Jurusan Gradasi Teknik Sipil Politeknik Negeri Banjarmasin, Jl. Brigjen H. Hasan Basri 70123 Banjarmasin Telp/Fax 0511-3307757; Email: gradasi.tekniksipil@poliban.ac.id 


\section{JURNAL GRADASI TEKNIK SIPIL}

\section{DAFTAR ISI}

Perencanaan Campuran Lapis Aspal Beton Permukaan Dengan Asbuton Butir Sebagai Filler ...( 1 - 9 )

Surat, Rifanie Gazalie, Pazilatul Mumamiroh

Pengaruh Keberadaan Pasar Sungai Lulut Terhadap Kinerja Jalan Martapura Lama KM. 05 ...( 10 - 19)

\section{Riska Hawinuti}

Analisis Perbandingan Biaya Penggunaan Perancah Kayu Galam Dan Perancah Besi (Scaffolding) ...( $20-32)$ Aunur Rafik, Rinova Firman Cahyani

Tinjauan Debit Andalan untuk Irigasi di Kecamatan Sungai Tabuk Kabupaten Banjar ...( $33-43)$

Fakhrurrazi, Herliyani Farial Agoes, Desi Anggeriyani

Ekosemen Sebagai Media Perekat Pengganti Semen Untuk Beton ...( 44 - 51 ) Marhadi Sastra, Juli Ardita Pribadi R

Pengaruh Posisi, Jumlah Layer Dan Mutu Kayu Terhadap Balok Laminasi Kayu Mahang Dan Kayu Meranti ...( 52 - 60 )

\section{Indriyani Puluhulawa}

Visualisasi Dan Identifikasi Pola Retak Dinding Bata Akibat Penurunan Pondasi Struktur Bangunan Di Kota Banjarmasin ...( 61 - 68 )

\section{Darmansyah Tjitradi, Eliatun}

Pengembangan Perumahan Dengan Desain Konstruksi Dilahan Basah Pada Wilayah Kota Banjarmasin Menggunakan Riset Operasi ...( 69 - 75 )

\section{Eliatun, Darmansyah Tjitradi}




\title{
Analisis Perbandingan Biaya Penggunaan Perancah Kayu Galam Dan Perancah Besi (Scaffolding)
}

\author{
Aunur Rafik ${ }^{1}$, Rinova Firman Cahyani ${ }^{2 *}$ \\ ${ }^{1,2}$ Dosen Jurusan Teknik Sipil Politeknik Negeri Banjarmasin \\ e-mail: ${ }^{1}$ rafik@poliban,.ac.id, ${ }^{2}$ rinovafc@poliban.ac.id (corresponding author)
}

\begin{abstract}
Abstrak
Perancah merupakan konstruksi pembantu pada pekerjaan bangunan gedung. Perancah dibuat apabila pekerjaan bangunan gedung mencapai ketinggian lebih dari 2 meter dan tidak dapat dijangkau oleh pekerja. Karena ketersediaan kayu galam di Banjarmasin semakin langka, untuk itu perlu dilakukan pencarian alternatif bahan lain perancah yang lebih awet, mudah didapat dan bisa dipakai berulang kali. Salah satunya adalah perancah besi (scaffolding). Pada penelitian ini akan dihitung biaya penggunaan perancah kayu galam dan perancah besi dalam harga beli dan sewa guna mengetahui jenis perancah mana yang lebih ekonomis untuk digunakan.

Metode yang digunakan pada penelitian ini adalah metode deskriptif dan metode komparatif. Lokasi pengambilan data pada pembangunan gedung Kantor Badan Pusat Statistik (BPS) Provinsi Kalimantan Selatan di Jl Trikora Banjarbaru dan ruko 3 lantai.di Jl. Benua Anyar Banjarmasin.

Berdasarkan perhitungan dalam luasan $1 \mathrm{~m} 2$ diperoleh biaya pekerjaan perancah kayu galam sebesar Rp. 147.057,81,-, pekerjaan perancah besi dalam harga sewa Rp. 201.033,81 dan biaya perancah besi dalam harga beli Rp. 2.214.161,06. Dari hasil tersebut didapat biaya pekerjaan perancah kayu galam 26,85\% lebih murah dibanding perancah besi dalam harga sewa. dan 15 kali biaya perancah besi dalam harga beli.
\end{abstract}

Kata kunci-Perancah Kayu Galam, Perancah Besi (Scaffolding), RAB, Harga Sewa, Harga Beli

\begin{abstract}
A scaffolding is a construction helper on building construction work. The scaffolding is made when the building work occupies a height of more than 2 meters and can not be reached by the workers. Because of the availability of galam wood in Banjarmasinis increasingly rare, thus the search for alternative material for scaffolding that is more durable, easier to get and can be used repeatedly is necessary to conduct. One of them is iron scaffolding. This research calculated and compared the cost of using galam wood scaffolding and iron scaffolding in the purchase price and rental price to find out which type of scaffolding is more economical to use.

The method used in this research was descriptive method and comparative method. The locations of data retrieval were on the construction of Central Bureau of Statistics Office (BPS) South Kalimantan Province on Jl Trikora Banjarbaru and 3-storey building on Jl. Banua Anyar Banjarmasin.

Based on the calculation in the area of $1 \mathrm{~m} 2$ the cost of galam wood scaffolding work of Rp. 147,057,81, -, the iron scaffolding work in rental price of $R p .201,033,81$ and the cost of iron scaffolding in the purchase price of Rp. 2,214,161,06 obtained. These results showed that the cost of galam wood scaffolding work $26.85 \%$ cheaper than the iron scaffolding in the rental price and 15 times the cost of iron scaffolding in the purchase price.
\end{abstract}

Keywords - Galam Wood Scaffolding, Iron Scaffolding, Budget Planning (RAB), Rental Price, Purchase Price 


\section{PENDAHULUAN}

Galam merupakan tumbuhan unik yang tumbuh pada lahan rawa di wilayah Kalimantan Selatan. Kayu galam ini merupakan komoditas penting karena digunakan untuk bahan utama pondasi bangunan pada lahan rawa dan sebagai perancah pada saat pekerjaan struktur. Berdasarkan pantauan saat ini keberadaannya semakin langka dikarenakan konversi lahan hutan menjadi lahan pertanian dan permukiman sebagai dampak lajunya pertumbuhan populasi penduduk.

Karena ketersediaan kayu galam di Banjarmasin semakin langka, untuk itu perlu dilakukan pencarian alternatif bahan lain perancah yang lebih awet, mudah didapat dan dapat dipakai berulang kali. Salah satunya adalah perancah besi. Perancah dibuat apabila pekerjaan bangunan gedung mencapai ketinggian lebih dari dua meter dan tidak dapat dijangkau oleh pekerja. Pekerjaan perancah berfungsi sebagai penahan cetakan (bekisting), balok dan pelat lantai sebelum pekerjaan cor-coran. Pemasangan perancah harus benar-benar kokoh dan mampu untuk menahan beban yang akan diterima setelah pekerjaan cor-coran dilakukan. Pada penelitian ini akan dihitung biaya penggunaan perancah kayu galam dan perancah besi dalam harga beli dan sewa guna mengetahui jenis perancah mana yang lebih ekonomis untuk digunakan.

Penelitian Terdahulu

Berdasarkan "Kajian Pemilihan Jenis Bahan Perancah Beton pada Pembangunan Gedung Bertingkat" di Semarang yaitu pada penelitian yang dilakukan oleh Suparno (2012) dengan pengolahan data menggunakan metode Analytic Hierarchy Process (AHP) terhadap penilaian pembuatan beton berdasarkan pemilihan jenis bahan perancah yang meliputi faktor biaya, efektifitas waktu, kekuatan dan keawetan, K3 dan dampak lingkungan dalam rangka mengkaji, membandingkan dan menilai ketiga alternatif jenis perancah disimpulkan jenis perancah besi dinilai sebagai jenis perancah yang paling baik (total score 0,531) dibanding perancah bamboo (total score 0,301 ) dan perancah kayu (total score 0,168$)$
Mengacu pada penelitian yang dilakukan oleh Astina, I Nyoman, (2015) yang berjudul "Value Engineering antara Perancah Konvensional dengan Scaffolding pada Konstruksi" (Studi Kasus : Gedung Bertingkat SMPN 10 Denpasar Bali yang hasil penelitiannya menyimpulkan bahwa penggunaan perancah konvensional lebih murah daripada scaffolding. Namun pemilihan cara konvensional perlu memperhatikan waktu pelaksanaan proyek agar waktu yang tersedia tidak tersedot untuk kegiatan bongkar pasang perancah ini dan penghematan biaya proyek terutama biaya tenaga kerja.

\section{Perancah}

Menurut Heinz, Frick dan Pujo. L Setiawan (2007), perancah adalah konstruksi dari batang bambu, kayu, atau pipa baja (scaffolding) yang didirikan ketika suatu gedung sedang dibangun untuk menjamin tempat kerja yang aman bagi tukang yang membangun gedung, memasang sesuatu atau mengadakan pekerjaan pemeliharaan.

\section{Spesifikasi Perancah}

Secara umum persyaratan perancah (Ratnasari, Yudit H., 2015; Sumargo, 2006) pada suatu konstruksi ialah :

a) Kuat. Perancah yang digunakan harus kuat menahan beton segar, getaran, peralatan yang digunakan, berat sendiri, berat orang yang bekerja dan pengaruh kejutan.

b) Kaku. Perancah harus kaku terutama akibat beban horizontal yang membuat cetakan mudah goyang dan tidak boleh melebihi deformasi yang diijinkan.

c) Kokoh. Perancah mampu menghasilkan bentuk penampang beton seperti yang diharapkan tanpa mengalami perubahan bentuk yang berarti. Ukuran dan kedudukan cetakan sesuai dengan gambar perencanaan.

d) Bersih. Saat pengecoran kotoran dapat naik dan masuk ke dalam adukan beton.

e) Mudah dibongkar. Dimaksudkan agar tidak merusak beton yang sudah jadi dan perancah dapat digunakan berkali-kali. 
f) Rapat. Sambungan pada cetakan harus rapat dan lubang yang disebabkan serangga harus ditutup sehingga cairan semen dan agregat tidak keluar dari cetak sambungan.

g) Material. Bahan yang digunakan harus mudah dipaku atau disekrup sehingga dalam membuat cetakan mudah dirangkai.

h) Optimal. Kebutuhan bahan dan tenaga kerja seefektif dan seefisien mungkin sehingga menguntungkan semua pihak.

\section{Rencana Anggaran Biaya ( RAB )}

Menurut Mukomoko (1987) Rencana Anggaran Biaya (RAB) Proyek adalah perkiraan nilai biaya dari suatu kegiatan (proyek) yang telah memperhitungkan gambar-gambar bestek serta rencana kerja, daftar upah, daftar harga bahan, buku analisa, daftar susunan rencana biaya, serta daftar jumlah tiap jenis pekerjaan.

Menurut Badan Standardisasi Nasional (BSN) (2008), Analisa Anggaran Biaya Konstruksi memiliki dua macam persyaratan yaitu :

1. Persyaratan umum

Persyaratan umum dalam perhitungan harga satuan:

a. Perhitungan harga satuan pekerjaan berlaku untuk seluruh wilayah Indonesia, berdasarkan harga bahan dan upah kerja sesuai dengan kondisi setempat.

b. Spesifikasi dan cara pengerjaan setiap jenis pekerjaan disesuaikan dengan standar teknisi pekerjaan yang telah dibakukan.

2. Persyaratan teknis

Persyaratan teknis dalam perhitungan harga satuan pekerjaan:

a. Pelaksanaan perhitungan satuan pekerjaan harus didasarkan pada gambar teknis dan rencana kerja serta syarat-syarat (RKS).

b. Perhitungan indeks bahan telah ditambahkan toleransi sebesar 5\% - 20\%, dimana didalamnya termasuk angka susut yang besarnya tergantung dari jenis bahan dan komposisi adukan.

c. Jam kerja efektif untuk tenaga kerja diperhitungkan 5 jam perhari.
Biaya Pekerjaan

Menurut Soedrajat (1994) ada lima hal pokok dalam menghitung biaya, yaitu: (1) bahan - bahan: menghitung banyaknya bahan yang dipakai dan harganya; (2) buruh: menghitung jam kerja yang diperlukan dan jumlah biayanya; (3) peralatan: menghitung jenis dan banyaknya peralatan yang dipakai dan biayanya; (4) overhead: menghitung biaya-biaya tidak terduga yang perlu diadakan dan (5) profit: menghitung persentase keuntungan dari waktu, tempat dan jenis pekerjaan.

\section{Dasar Perhitungan Rencana Anggaran Biaya}

Pada dasarnya setiap perhitungan rencana anggaran biaya umumnya (menurut buku standar analisa) memiliki empat faktor yang dibutuhkan meliputi (1) harga bahan-bahan setempat; (2) harga upah pekerja/tukang setempat; (3) keamanan di tempat pekerjaan dan (4) Transport material ke tempat pekerjaan

Faktor-Faktor dalam Menghitung Rencana Anggaran Biaya.

Faktor-faktor yang terkait dalam menghitung anggaran biaya adalah :

1. Harga satuan bahan adalah harga yang sesuai dengan satuan jenis bahan bangunan tersebut.

2. Harga satuan pekerjaan adalah harga yang dihitung berdasarkan analisis harga satuan bahan dan upah.

3. Indeks adalah faktor pengali atau koefisien sebagai dasar penghitungan biaya bahan dan upah kerja.

4. Indeks bahan adalah indeks kuantum yang menunjukkan kebutuhan bahan bangunan untuk setiap jenis pekerjaan.

5. Indeks tenaga kerja adalah indeks kuantum yang menunjukkan kebutuhan waktu untuk mengerjakan setiap jenis satuan jenis pekerjaan.

6. Satuan pekerjaan adalah suatu jenis kegiatan konstruksi bangunan yang dinyatakan dalam satuan-satuan panjang, luas, volume dan unit.

\section{METODE PENELITIAN}

Metode penelitian yang digunakan adalah metode deskriptif dan metode komparatif. Metode 
deskriptif digunakan untuk mendeskripsikan pekerjaan perancah guna menghitung biaya perancah kayu galam, biaya perancah besi dalam harga beli dan harga sewa. Sedangkan metode komparatif digunakan untuk membandingkan biaya pekerjaan perancah kayu galam dengan biaya pekerjaan perancah besi dalam harga sewa dan untuk membandingkan biaya pekerjaan perancah kayu galam dengan biaya pekerjaan perancah besi dalam harga beli.

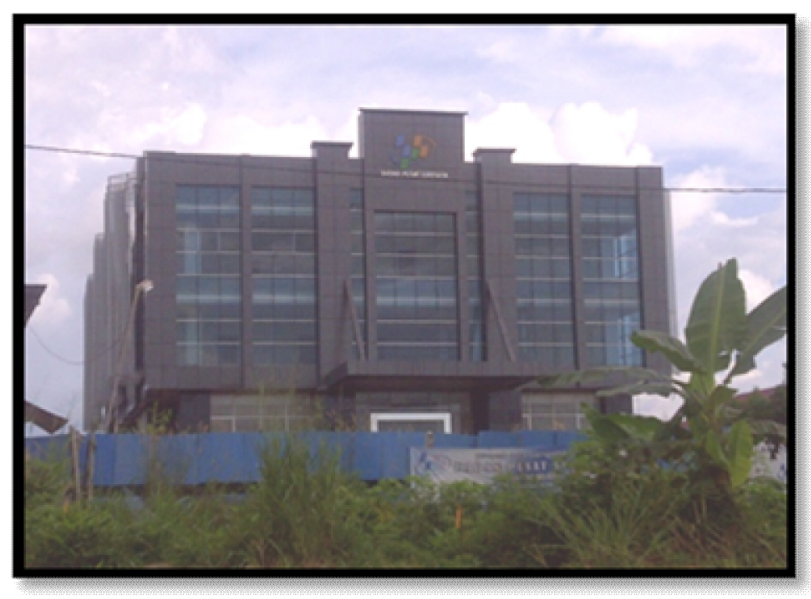

Gambar 1a. Proyek di BPS Propinsi Kalimantan Selatan
Lokasi penelitian :

a. Pada pembangunan Gedung Kantor Badan Pusat Statistik(BPS)

Provinsi Kalimantan Selatan di Jl TrikoraBanjarbaru

b. Pada pembangunan ruko 3 lantai di Jl. Benua Anyar Banjarmasin.

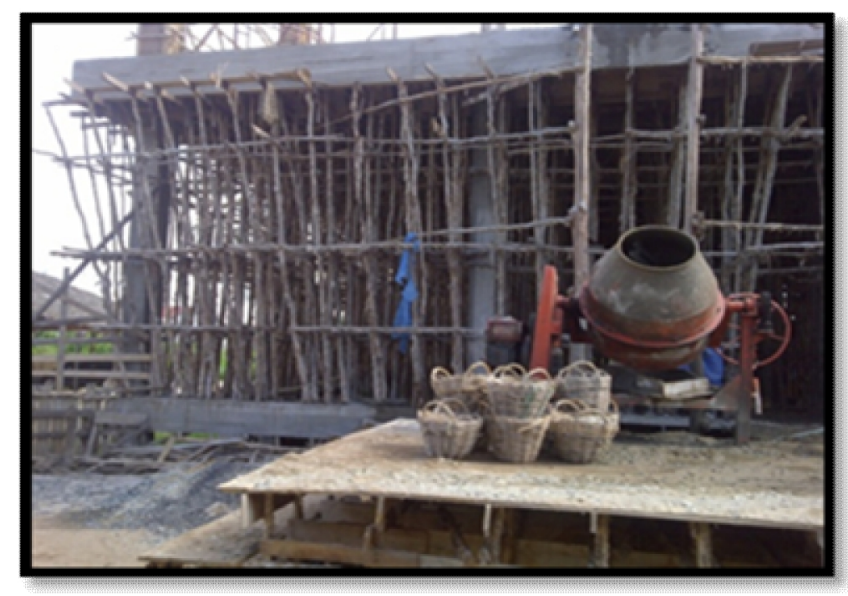

Gambar 1b. Proyek Ruko 3 lantai Banua Anyar Banjarmasin

Tahapan penelitian dapat dilihat pada Gambar 2.

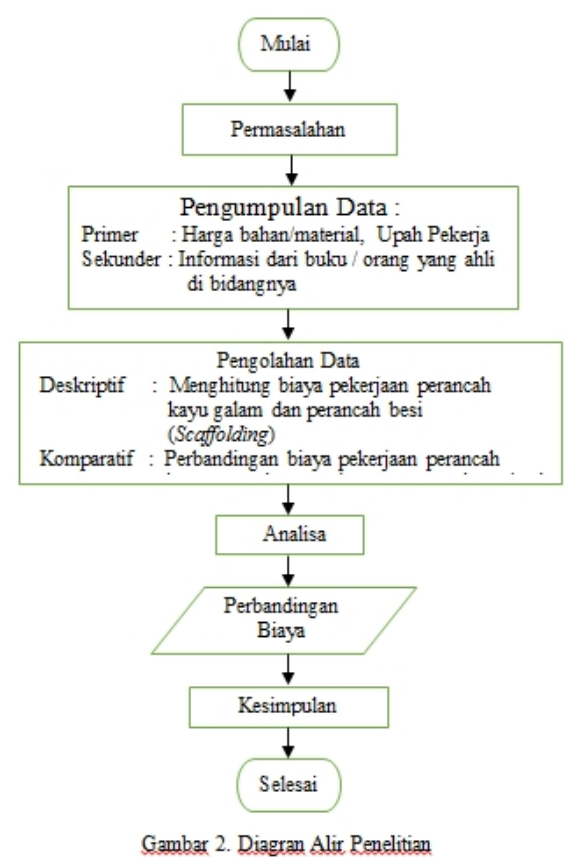




\section{HASIL DAN PEMBAHASAN}

Pekerjaan pemasangan perancah kayu galam diaplikasikan pada Proyek Kantor Badan Pusat Satistik (BPS) Provinsi Kalimantan Selatan di

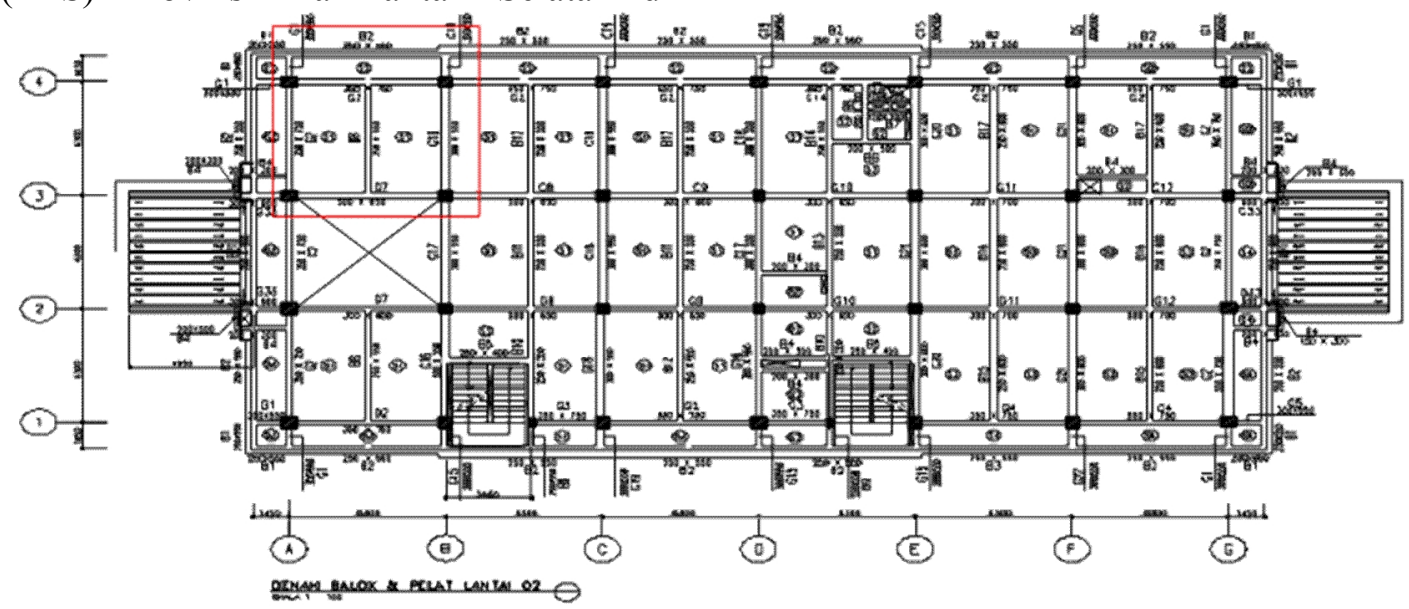

Gambar 3. Denah Rencana Pemasangan Perancah dengan Luasan $6.30 \mathrm{~m} \mathrm{X} 6.30 \mathrm{~m}=36.96 \sim 40 \mathrm{~m} 2$

A. Pelaksanaan Pekerjaan Perancah Kayu 1. Pekerjaan persiapan yaitu dengan Galam

A.1 Pekerjaan pada Lantai

Langkah-langkah pemasangan perancah pada lantai sebagai berikut :

1. Dirikan tiang-tiang perancah kayu galam induk Ø $5-7 \mathrm{~cm}$, panjang $4 \mathrm{~m}$, berjarak $30-50 \mathrm{~cm}$.

2. Rangkaikan (suri-suri) kayu galam anak Ø 3

$-5 \mathrm{~cm}$, panjang $4 \mathrm{~m}$ pada perancah kayu galam induk,

secara horizontal dengan jarak $1 \mathrm{~m}$.

3. Gelagar acuan $2 / 10$ jarak $50 \mathrm{~cm}$, dipakukan pada tiang - tiang perancah yang tingginya berpedoman

pada benang / unting - unting yang telah ditegakkan / dikencangkan dari tiang perancah ujung sampai

pangkal.

4. Multiplek dipakukan pada gelagar - gelagar acuan ( dari papan (2/10) dan juga pada cetakan balok

bagian sisi yang berhubugan dengan lantai.

5. Pengontrolan.

\section{A.2 Pekerjaan pada Balok 25/40}

Langkah - langkah pekerjaan perancah pada lantai sebagai berikut :.
Banjarbaru dalam perbandingan harga diambil luas bangunan 6,3 m x 6,3 m. Denah rencana pemasangan perancah dapat dilihat pada Gambar 3 . memasang benang / unting -unting sebagai dasar untuk mengetahui kedataran balok - balok terhadap bidang tegak lurus nya unting - unting sehingga nanti setelah pengecoran, balok - balok benar benar tegak lurus terhadap kolom.

2. Rangkai papan - papan acuan dengan menggunakan klam sebagai sisi - sisi penguat cetakan balok;

3. Jarak antara klam - klam ( Papan 2/10 ) 30 $-50 \mathrm{~cm}$

4. Dirikan galam induk $\varnothing 5-8 \mathrm{~cm}$ dalam keadaan vertikal, sejarak dengan klam.

5. Pemasangan gelagar

6. Menggunakan papan 2/10, dan menggunakan pendukung papan kayu $2 / 10$ yang diletakan diatas tiang - tiang perancah dan kedudukan balok pendukung harus betul - betul rata / horizontal;

7. Pada gelagar acuan dipakukan pada balok balok pendukung / perancah dan tiang - tiang acuan. Gelagar acuan permukaanya harus rata / horizontal;

8. Pakukan papan cetakan balok sisi atas dan balok sisi bawah terhadap gelagar acuan;

9. Bagian sisi tegak dapat diperkuat dengan papan pada klam - klam perangkai sisi acuan. 
10. Papan acuan balok bagian sisi bawah dapat dipakukan pada gelagar papan aacuan, untuk papan cetakan bagian sisi tegaknya dapat diperkuat dengan papan - papan penguat pada klam - klam perangkai papan cetakan;
11. Pengontrolan

A.3 Denah Rencana Pemasangan Perancah Kayu Galam

Denah rencana pemasangan perancah kayu galam dapat dilihat pada Gambar 4.

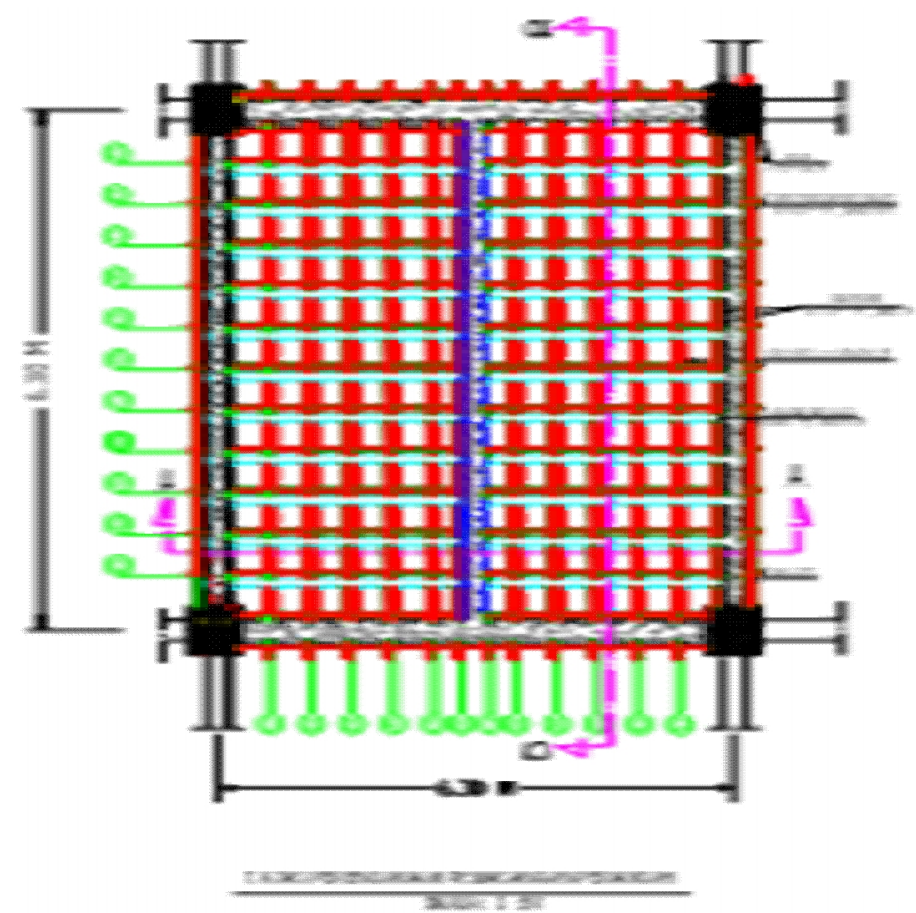

Gambar 4. Denah Rencana Pemasangan Perancah Kayu Galam

Pekerjaan gelagar kayu lanan 2/10 dapat dilihat pada Gambar 5.

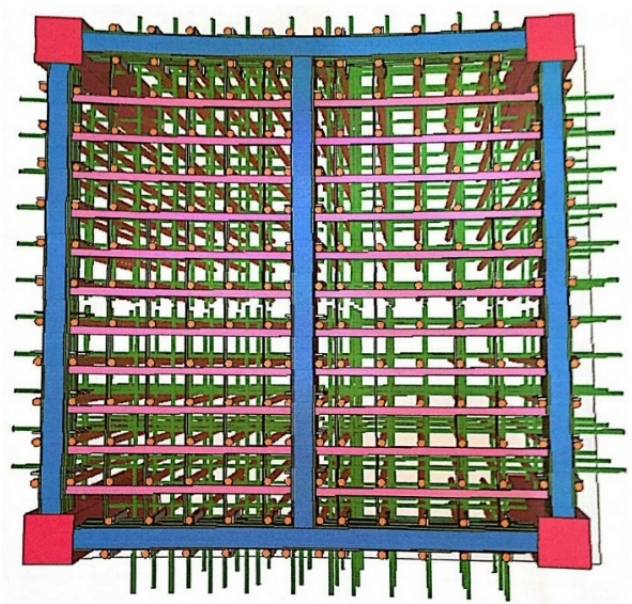

Gambar 5. Gelagar Papan kayu Lanan 2/10 
Tampak depan pemasangan perancah kayu galam dapat dilihat pada Gambar 6 .

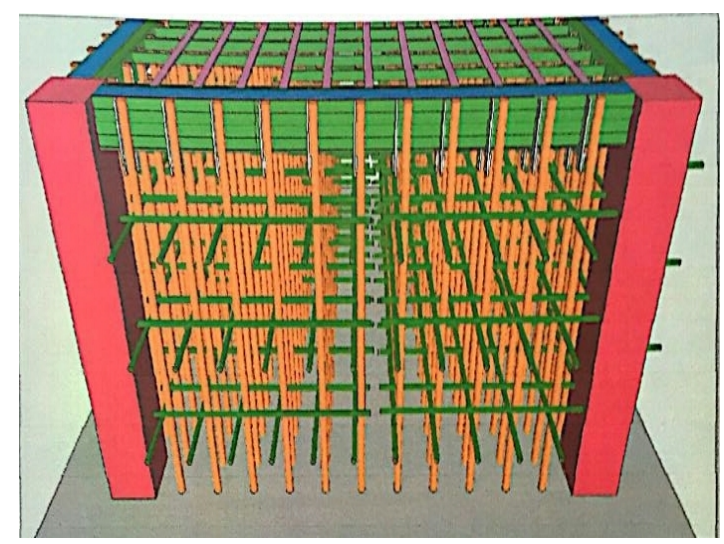

Gambar 6. Tampak Depan Pemasangan Perancah Kayu Galam

\section{A.4 Anggaran Biaya Pekerjaan Perancah Kayu Galam}

Anggaran biaya pekerjaan perancah kayu galam dapat dilihat pada Tabel 1.

Tabel 1. Anggaran Biaya Pekerjaan Kayu Galam

Tabel 1. Anggaran Biaya Pekerjaan Kayu Galam

\begin{tabular}{|l|l|r|r|r|r|r|}
\hline NO & URAIAN PEKERJAAN & VOL. & SAT. & $\begin{array}{r}\text { HARGA } \\
\text { SATUAN(Rp) }\end{array}$ & $\begin{array}{r}\text { MATERIAL/ } \\
\text { BAHAN(Rp) }\end{array}$ & $\begin{array}{r}\text { JUMLAH } \\
\text { (Rp) }\end{array}$ \\
\hline 1 & Kayu Galam Induk $\varnothing 5-8$, panjang 4 m & 246,00 & $\mathrm{btg}$ & $4.000,00$ & $984.000,00$ & $984.000,00$ \\
\hline 2 & Kayu Galam Anak $\varnothing 3-5$, panjang 4 $\mathrm{m}$ & 186,00 & $\mathrm{btg}$ & $2.500,00$ & $465.000,00$ & $465.000,00$ \\
\hline 3 & Papan Kayu Lanan 2/10 & 1,03 & $\mathrm{m3}$ & $1.562 .500,00$ & $1.607 .812,50$ & $1.607 .812,50$ \\
\hline 4 & Paku Ukuran 2 inchi & 9,00 & $\mathrm{Kg}$ & $14.000,00$ & $126.000,00$ & $126.000,00$ \\
\hline 5 & Paku Ukuran 3 inchi & 3,00 & $\mathrm{Kg}$ & $14.000,00$ & $42.000,00$ & $42.000,00$ \\
\hline 6 & Plywood Ukuran 12 mm & 12,50 & $\mathrm{Lbr}$ & $165.000,00$ & $2.062 .500,00$ & $2.062 .500,00$ \\
\hline 7 & Mandor & 1,00 & Org/hr & $90.000,00$ & - & $90.000,00$ \\
\hline 8 & Kepala Tukang & 1,00 & $\mathrm{Org} / \mathrm{hr}$ & $85.000,00$ & - & $85.000,00$ \\
\hline 9 & Tukang Kayu & 3,00 & $\mathrm{Org} / \mathrm{hr}$ & $75.000,00$ & - & $225.000,00$ \\
\hline 10 & Pekerja/Buruh & 3,00 & $\mathrm{Org} / \mathrm{hr}$ & $65.000,00$ & - & $195.000,00$ \\
\hline & Jumlah & & & $\mathbf{5 . 2 8 7 . 3 1 2 , 0 0}$ & $\mathbf{5 . 8 8 2 . 3 1 2 , 0 0}$ \\
\hline & & & & & \\
\hline
\end{tabular}

(Sumber : Hasil Perhitungan)

\section{A. Pekerjaan Perancah Besi Galvanis (Scaffolding)}

\section{B.1 Pemasangan Frame Jarak 180 Cm (Tipe A)}

Pemasangan frame jarak $180 \mathrm{~cm}$ (tipe A) sebagai berikut :

1. Memasang Base Jack pada pada lantai kerja (lantai beton)

2. Pemasangan Frame Mf-190, pada Base Jack

3. Memasang Cross Brace cb-1218 1220 galv ke main frame mf sebagai penguat frame agar berdiri tegak. 
4. Memasang Joint Pin sebagai penyambung antara Frame $190 \mathrm{~cm}$ dengan Frame $90 \mathrm{~cm}$

5. Memasang Frame Lf- 901209 Galv

6. Memasang Cross Brace Cb-0618 L 193 Galv

7. Memasang U-Head Jack UHJ-60, pada Frame 90

\section{B.2 Pemasangan Frame Jarak 90 Cm (Tipe B)}

Pemasangan Frame Jarak $90 \mathrm{~cm}$ (tipe B) sebagai berikut :

1a. - Pasang Base Jack (BJ) pada posisinya dengan jarak $90 \mathrm{~cm}$ antara BJ 1a dg 2a dan 2a dg 3a dst.

- Bedakan tinggi spindle-nya minimal $\mathbf{5} \mathbf{~ c m}$ antara BJ 1a dg 2a, agar pada saat pemasangan Cross Brace nanti tidak sangkut terhadap Frame 190.

- Atur agar sama tingginya antara spindle dalam kelipatan BJ $180 \mathrm{~cm}$ karena akan menjadi pasangan pada saat pemasangan Cross Brace CB 220.

1b. - Pemasangan spindle 1b, 2b, 3b dst. mengikuti langkah pemasangan BJ 1a, 2a, 3a, dst. dengan jarak $120 \mathrm{~cm}$ antara BJ 1a dengan BJ 1b

2. Pasang Main Frame MF-190 pada setiap posisi Base Jack (BJ).

3. Pasang Cross Brace Scaffolding 1a-3a di ikuti dengan pemasangan Cross Brace Scaffolding 1b-3b.

4. Selanjutnya pasang Cross Brace Scaffolding 2a-4a dan di ikuti pemasangan

Cross Brace Scaffolding 2b-4b.

\section{B.3 Pemasangan Kayu Balok pada Scaffolding}

Pemasangan kayu balok pada scaffolding sebagai berikut :

1. Memasang balok 5/7 pada $u$-head jack (suri-suri).

2. Memasang balok engkelan $4 / 6-150 \mathrm{~cm}$ (gelagar)

3. Memasang bekisting papan $2 / 10$ dan perkuat nya balok $4 / 6$

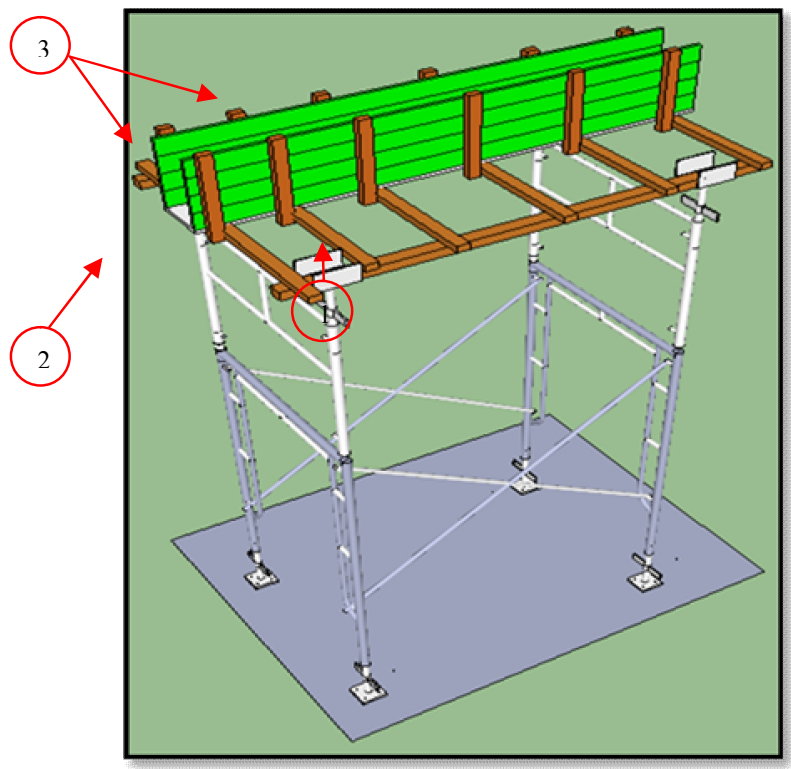

Gambar 7. Pemasangan Balok pada Balok 25/40 


\section{B.4 Pemasangan Hory Beam}

Pemasangan hory beam dapat dilihat pada Gambar 8.

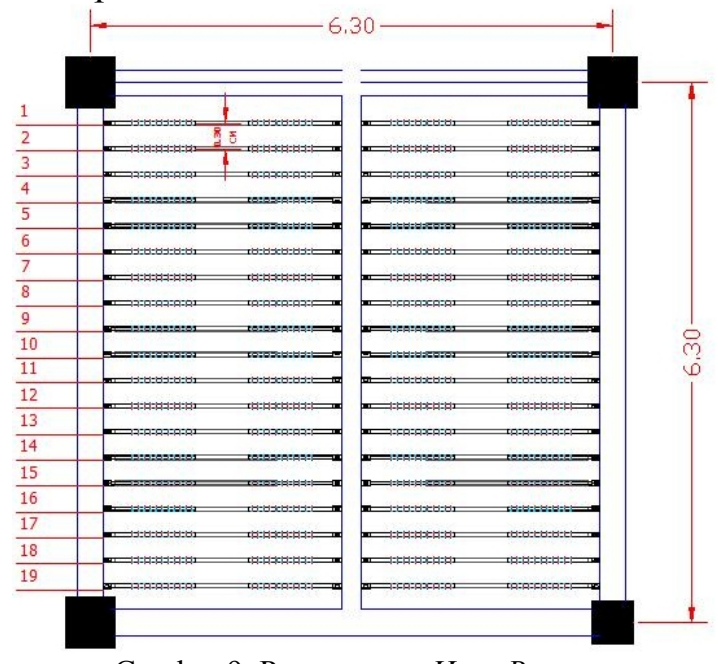

Gambar 9. Pemasangan Hory Beam

\section{B.5 Pekerjaan Suri-suri Balok 5/7 dan Gelagar Balok 4/6}

Pekerjaan suri-suri balok 5/7 dan gelagar 4/6 dapat dilihat pada Gambar 9.

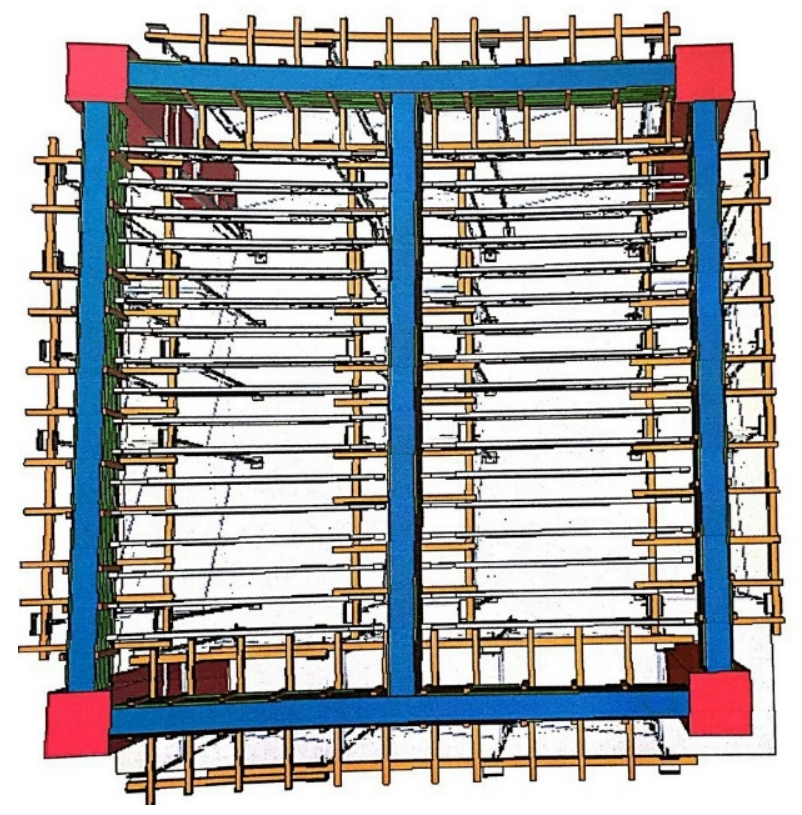

Gambar 9. Pekerjaan Suri-suri Balok 5/7 dan Gelagar Balok 4/6 
Tampak depan pemasangan perancah besi pada Gambar 10.

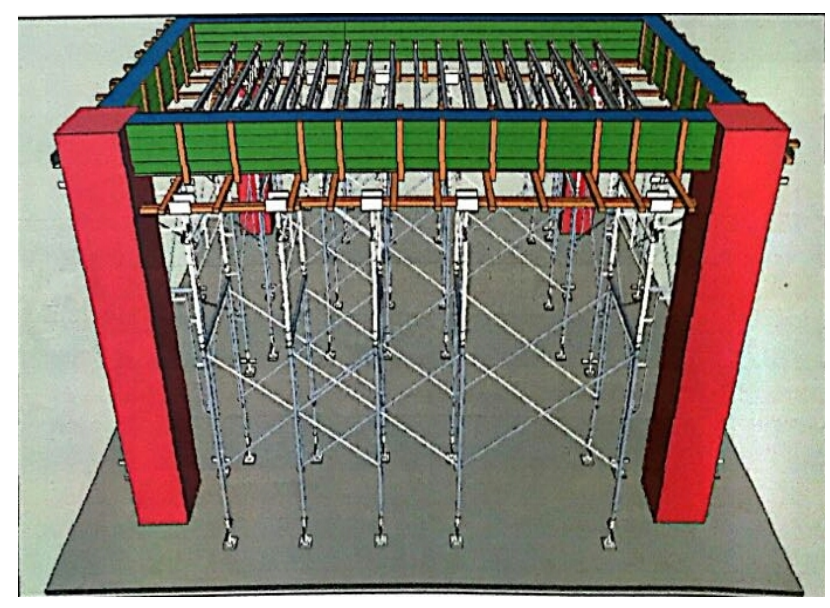

Gambar 10. Tampak Depan Pemasangan Perancah Besi(Scaffolding)

\section{B.6 Anggaran Biaya Pekerjaan Perancah Besi dalam Harga Sewa}

Anggaran biaya pekerjaan perancah besi dalam harga sewa dapat dilihat pada Tabel 2.

Tabel 2. Anggaran Biaya Pekerjaan Perancah Besi dalam Harga Sewa

\begin{tabular}{|l|l|l|l|r|r|r|}
\hline NO & URAIAN PEKERJAAN & VOL. & SAT. & \multicolumn{1}{|l|}{$\begin{array}{l}\text { HARGA } \\
\text { SATUAN(Rp) }\end{array}$} & $\begin{array}{l}\text { MATERIAL/ } \\
\text { BAHAN(Rp) }\end{array}$ & \multicolumn{1}{l|}{$\begin{array}{l}\text { JUMLAH } \\
\text { (Rp) }\end{array}$} \\
\hline 1 & Frame Mf- 190 1219 Galv & 23,00 & bh & $24.400,00$ & $561.200,00$ & $561.200,00$ \\
\hline 2 & Frame Lf- 90 1209 Galv & 23,00 & bh & $13.900,00$ & $319.700,00$ & $319.700,00$ \\
\hline 3 & Base Jack Bj-BJ-60 & 46,00 & bh & $7.200,00$ & $331.200,00$ & $331.200,00$ \\
\hline 4 & U-Head Jack UHJ-60 & 46,00 & bh & $7.700,00$ & $354.200,00$ & $354.200,00$ \\
\hline 5 & Joint Pin D 36 Galv & 46,00 & bh & 800,00 & $36.800,00$ & $36.800,00$ \\
\hline 6 & Cross Brace Cb-1218 L220 Galv & 60,00 & bh & $6.800,00$ & $408.000,00$ & $408.000,00$ \\
\hline 7 & Cross Brace Cb-0618 L1 Galv & 60,00 & bh & $6.000,00$ & $360.000,00$ & $360.000,00$ \\
\hline 8 & Hory Beam & 38,00 & bh & $47.630,00$ & $1.809 .940,00$ & $1.809 .940,00$ \\
\hline 9 & Balok Kayu Lanan 5/7 & 0,192 & $\mathrm{~m} 3$ & $2.500 .000,00$ & $480.000,00$ & $480.000,00$ \\
\hline 10 & Balok Kayu Lanan 4/6 & 0,257 & $\mathrm{~m} 3$ & $2.812 .500,00$ & $722.812,50$ & $722.812,50$ \\
\hline 11 & Plywood 12 mm & 12,50 & $\mathrm{lbr}$ & $165.000,00$ & $1.062 .500,00$ & $2.062 .500,00$ \\
\hline 12 & Mandor & 1,00 & Org/hr & $90.000,00$ & - & $90.000,00$ \\
\hline 13 & Kepala Tukang & 1,00 & Org/hr & $85.000,00$ & - & $85.000,00$ \\
\hline 14 & Tukang Kayu & 3,00 & Org/hr & $75.000,00$ & - & $225.000,00$ \\
\hline 15 & Pekerja/Buruh & 3,00 & Org/hr & $65.000,00$ & - & $195.000,00$ \\
\hline & Jumlah & & & & $\mathbf{7 . 4 4 6 . 3 5 2 , 5 0}$ & $\mathbf{8 . 0 4 1 . 3 5 2 , 5 0}$ \\
\hline
\end{tabular}




\section{B.7 Anggaran Biaya Pekerjaan Perancah Besi dalam Harga Beli}

Anggaran biaya pekerjaan perancah besi dalam harga beli sebagai berikut :

Tabel 3. Anggaran Biaya Pekerjaan Perancah Besi dalam Harga Beli

\begin{tabular}{|c|c|c|c|c|c|c|}
\hline NO & URAIAN PEKERJAAN & VOL. & SAT. & $\begin{array}{l}\text { HARGA } \\
\text { SATUAN(Rp) }\end{array}$ & $\begin{array}{l}\text { MATERIAL/ } \\
\text { BAHAN(Rp) }\end{array}$ & $\begin{array}{l}\text { JUMLAH } \\
\text { (Rp) }\end{array}$ \\
\hline 1 & Frame Mf- 1901219 Galv & 23,00 & bh & $497.700,00$ & $11.447 .100,00$ & $11.447 .100,00$ \\
\hline 2 & Frame Lf- 901209 Galv & 23,00 & bh & $282.500,00$ & $6.497 .500,00$ & $6.497 .500,00$ \\
\hline 3 & Base Jack Bj-BJ-60 & 46,00 & bh & $146,000,00$ & $6.716 .000,00$ & $6.716 .000,00$ \\
\hline 4 & U-Head Jack UHJ-60 & 46,00 & bh & $156.500,00$ & $7.199 .000,00$ & $7.199 .000,00$ \\
\hline 5 & Joint Pin D 36 Galv & 46,00 & bh & $16.800,00$ & $772.800,00$ & $772.800,00$ \\
\hline 6 & Cross Brace Cb-1218 L220 Galv & 60,00 & bh & $139.700,00$ & $8.382 .000,00$ & $8.382 .000,00$ \\
\hline 7 & Cross Brace Cb-0618 L1 Galv & 60,00 & bh & $123.900,00$ & $7.434 .000,00$ & $7.434 .000,00$ \\
\hline 8 & Hory Beam & 38,00 & bh & $960.960,00$ & $36.516 .480,00$ & $36.516 .480,00$ \\
\hline 9 & Balok Kayu Lanan 5/7 & 0,19 & $\mathrm{m3}$ & $2.500 .000,00$ & $480.000,00$ & $480.000,00$ \\
\hline 10 & Balok Kayu Lanan 4/6 & 0,17 & $\mathrm{~m} 3$ & $2.812 .500,00$ & $464.062,50$ & $464.062,50$ \\
\hline 11 & Plywood $12 \mathrm{~mm}$ & 12,50 & $\mathrm{lbr}$ & $165.000,00$ & $2.062 .500,00$ & $2.062 .500,00$ \\
\hline 12 & Mandor & 1,00 & Org/hr & $90.000,00$ & - & $90.000,00$ \\
\hline 13 & Kepala Tukang & 1,00 & Org/hr & $85.000,00$ & - & $85.000,00$ \\
\hline 14 & Tukang Kayu & 3,00 & Org/hr & $75.000,00$ & - & $225.000,00$ \\
\hline \multirow[t]{2}{*}{15} & Pekerja/Buruh & 3,00 & $\mathrm{Org} / \mathrm{hr}$ & $65.000,00$ & - & $195.000,00$ \\
\hline & Jumlah & & & & 88.230 .192 .50 & $88.566 .442,50$ \\
\hline
\end{tabular}

(Sumber : Hasil Perhitungan)

\section{A. Analisis Perbandingan Anggaran Biaya Pekerjaan Perancah}

Berdasarkan hasil perhitungan biaya perbandingan penggunaan perancah kayu galam dengan perancah besi (Scaffolding) didapatkan hasil sebagai berikut :

Tabel 4. Anggaran Biaya Pekerjaan Perancah dalam Luasan $40 \mathrm{~m}^{2}$ dan Luasan $1 \mathrm{~m}^{2}$

\begin{tabular}{|c|l|c|c|}
\hline No & Jenis Perancah & $\begin{array}{c}\text { Biaya dengan Luasan } 40 \mathrm{~m}^{2} \\
(\mathrm{Rp})\end{array}$ & $\begin{array}{c}\text { Biaya dengan luasan } 1 \mathrm{~m}^{2} \\
(\mathrm{Rp})\end{array}$ \\
\hline 1 & Perancah Kayu Galam & $5.882 .312,00$ & $147.057,81$ \\
\hline 2 & $\begin{array}{l}\text { Perancah Besi (Scaffolding) } \\
\text { dalam Harga Sewa }\end{array}$ & $8.041 .352,50$ & $201.033,81$ \\
\hline 3 & $\begin{array}{l}\text { Perancah Besi (Scaffolding) } \\
\text { dalam Harga Beli }\end{array}$ & $88.566 .442,50$ & $2.214 .161,06$ \\
\hline
\end{tabular}

Sedangkan untuk perancah besi biaya

Dari hasil perbandingan biaya pekerjaan perancah kayu galam dan perancah besi biaya pekerjaan perancah galam memang lebih murah akan tetapi bahan/material tidak dapat digunakan berulangulang karena bahan yang digunakan tidak utuh seperti semula. penggunaannya lebih mahal, namun dari segi waktu pemasangan lebih cepat dan praktis dibandingkan perancah kayu galam. Penggunaan Perancah besi juga dapat digunakan berulang-ulang dalam jangka waktu yang lama dan lebih kuat. 
Dari hasil perhitungan perbandingan perancah kayu galam dan perancah besi diperoleh :

1. Biaya penggunaan perancah kayu galam lebih murah $26,85 \%$ dibanding biaya perancah besi dalam harga sewa.

2. Biaya penggunaan perancah besi dalam harga beli 15 kali biaya perancah kayu galam.

3. Biaya penggunaan perancah besi dalam harga beli 11 kali biaya perancah besi dalam harga sewa.

\section{KESIMPULAN}

Berdasarkan analisis perhitungan dalam luasan 1 $\mathrm{m} 2$ diperoleh biaya pekerjaan perancah kayu galam sebesar Rp. 147.057,81,- , pekerjaan perancah besi dalam harga sewa Rp. 201.033,81,-. Biaya pekerjaan perancah kayu galam lebih murah $26,85 \%$ dibanding biaya perancah besi dalam harga sewa.

Biaya perancah besi dalam harga beli $\mathrm{Rp}$. 2.214.161,06,-. Biaya pekerjaan perancah besi dalam harga beli 15 kali biaya pekerjaan perancah kayu galam dan 11 kali biaya perancah besi dalam harga sewa.

Saran

Alternatif penggunaan perancah besi (scaffolding) lebih menguntungkan apabila digunakan dalam jumlah yang banyak pada proyek besar, namun apabila hanya untuk bangunan yang berukuran kecil sebaiknya menggunakan perancah kayu galam karena harganya lebih ekonomis.

Untuk mengetahui batasan luasan maksimum penggunaan perancah kayu galam dan luasan maksimum penggunaan perancah besi dapat dilakukan peninjauan ulang.

Penggunaan perancah besi dengan harga sewa memang lebih ekonomis dari pada penggunaan perancah besi dengan harga beli. Namun untuk perusahaan - perusahaan besar yang sering menangani proyek sebaiknya membeli perancah besi karena dapat digunakan berulang - ulang dan sebagai investasi perusahaan.

\section{UCAPAN TERIMA KASIH}

Syukur Alhamdulillaah penulis panjatkan kepada Allah SWT bahwa artikel ini dapat diselesaikan dengan baik dan tepat pada waktunya, di sela-sela padatnya aktifitas di kampus. Terima kasih yang tulus penulis sampaikan kepada pimpinan proyek pembangunan gedung BPS Provinsi Kalsel di Banjarbaru dan pimpinan proyek pembangunan Ruko 3 lantai di Banua Anyar Banjarmasin yang telah bersedia memberikan data dan informasi tentang perancah ini. Terima kasih tak terhingga juga penulis sampaikan kepada rekan-rekan di kampus yg telah meluangkan waktu dan tenaganya untuk membantu penerbitan artikel ini. Semoga Allah mencatatnya sebagai amal ibadah dan selalu memberkahi niat baik rekan-rekan semua. Semoga artilkel ini dapat bermanfaat bagi semua pihak yang memerlukan.

\section{REFERENSI}

Akhmad, Toriq, 1996, Petunjuk Kerja Acuan dan Perancah 2, Pusat Pengembangan Pendidikan Politeknik, Bandung.

Astina, I Nyoman, 2015, 'Value Engineering antara Perancah Konvensional dengan Scaffolding pada Proyek Konstruksi', Explorasi Jurnal Teknik Sipil Untag Surabaya, Vol.8, No. 1 hh. 49-62.

Heinz, Frick dan Pujo. L Setiawan, 2007, Ilmu Konstruksi Struktur Bangunan. Seri Konstruksi Arsitektur 4, Kanisius, Yogyakarta.

Mukomoko, J. A., 1987 , Dasar Penyusunan Anggaran Biaya Bangunan.Gaya Media Pratama, Jakarta

Ratnasari, Yudit H., 2015, Efisiensi Penggunaan Perancah Besi dan Perancah Bambu pada Pembangunan Gedung SKPD I Tipe A, Skripsi, Fakultas Teknik Universitas Gorontalo, Gorontalo.

Sarito, Trimanto, 1996, Petunjuk Kerja Acuan dan Perancah 1, Pusat Pengembangan Pendidikan Politeknik, Bandung.

SNI, 2008, Analisa Biaya Konstruksi, Badan Standardisasi Nasional (BSN).

Soedrajat, S.A.,1994, Anggaran Biaya Pelaksanaan (Analisa Modern), Nova, Bandung.

Sumargo, Ario Raja Nata, 2006, Keruntuhan Perancah Scaffolding Saat Pelaksanaan Pengecoran, Media Komunikasi Teknik Sipil 
Volume 14 No. 1 Edisi XXXIV Pebruari, Politeknik Negeri Bandung, Bandung.

Suparno, 2012, 'Kajian Pemilihan Jenis Bahan

Perancah Beton pada Pembangunan Gedung

Bertingkat', Wahana Jurnal Teknik Sipil

Politeknik Negeri Semarang,Vol. 17, No. 1, hh. 32-40. 